\title{
Thermochemical Studies on 3-Methyl-quinoxaline-2-carboxamide-1,4-dioxide Derivatives: Enthalpies of Formation and of N-O Bond Dissociation
}

\author{
José R. B. Gomes, ${ }^{\dagger}$ Emanuel A. Sousa, ${ }^{\dagger}$ Paula Gomes, ${ }^{\dagger}$ Nuno Vale, ${ }^{\dagger}$ Jorge M. Gonçalves, ${ }^{\dagger}$ \\ Siddharth Pandey, ${ }^{\ddagger}$ William E. Acree, Jr., ${ }^{\ddagger}$ and Maria D. M. C. Ribeiro da Silva*, ${ }^{\dagger}$ \\ Centro de Investigação em Química, Departamento de Química, Faculdade de Ciências, Universidade do \\ Porto, Rua do Campo Alegre, 687, P-4169-007 Porto, Portugal, and Department of Chemistry, University of \\ North Texas, Denton, Texas 76203-5070
}

Received: November 24, 2006; In Final Form: December 29, 2006

\begin{abstract}
The standard molar enthalpies of formation of the 3-methyl- $N$-R-2-quinoxalinecarboxamide-1,4-dioxides $(\mathrm{R}=\mathrm{H}$, phenyl, 2-tolyl) in the gas phase were derived using the values for the enthalpies of combustion of the crystalline compounds, measured by static bomb combustion calorimetry, and for the enthalpies of sublimation, measured by Knudsen effusion, at $T=298.15 \mathrm{~K}$. These values have also been used to calibrate a computational procedure that has been employed to estimate the gas-phase enthalpies of formation of the corresponding 3-methyl- $N$-R-2-quinoxalinecarboxamides and also to compute the first, second, and mean $\mathrm{N}-\mathrm{O}$ bond dissociation enthalpies in the gas phase. It is found that the size of the substituent almost does not influence the computed $\mathrm{N}-\mathrm{O}$ bond dissociation enthalpies; the maximum enthalpic difference is $\sim 5 \mathrm{~kJ} \cdot \mathrm{mol}^{-1}$.
\end{abstract}

\section{Introduction}

The quinoxaline derivatives show a high diversity of biological properties, having found application due to their antibacterial, antiviral, anticancer, antifungal, and insecticidal activities. ${ }^{1-5}$ Oxidation of one or both nitrogens of the quinoxaline ring highly increases the range of their interesting biological activities and DNA interactive behavior. These aspects justify the large number of recent studies reported in the literature, which may be considered as an effort to develop new and more potent bioreductive drugs. Indeed, the deep pharmacological and toxicological characterization and, at the same time, the improvement of the bioavailability of this class of polycyclic nitrogen-containing heterocycles have been extensively studied. ${ }^{6,7}$ Recently, functionalized quinoxaline-1,4-dioxides containing the 3-methyl-quinoxaline-2-carboxamide scaffold, and particularly the $N$-aryl derivatives, were found to be highly important due to their antimycobacterial activity.

The activity of heterocycles containing one or more $\mathrm{N}-\mathrm{O}$ bonds seems to be directly linked to the strength of their $\mathrm{N}-\mathrm{O}$ bonds, ${ }^{8}$ and therefore, it would be interesting to build a thermodynamic scale of the enthalpies of $\mathrm{N}-\mathrm{O}$ bond breaking in these compounds. In the literature, it is possible to find some research works that dealt with the construction of such a scale, but unfortunately, that is rather incomplete at the moment. Therefore, the thermochemical characterization of selected compounds that are representative of families of molecules already synthesized ${ }^{9-12}$ is one of our aims. To achieve our purposes, combustion and sublimation measurements, in combination with functional group contribution estimations and density-functional-theory-based computations, ${ }^{13}$ are being carried out in order to determine the mean molar dissociation enthalpy of the $\mathrm{N}-\mathrm{O}$ bonds, $\left\langle D H_{\mathrm{m}}^{\circ}(\mathrm{N}-\mathrm{O})\right\rangle$. The comparison of the $\mathrm{N}-\mathrm{O}$ bond dissociation enthalpies for compounds with different neighboring functional group substituents permits the

\footnotetext{
$\dagger$ Universidade do Porto.

$\doteqdot$ University of North Texas.
}

evaluation of the influence of such groups on the $\mathrm{N}-\mathrm{O}$ bond strength, improving the understanding of the oxidizing capabilities of these molecules.

The present work reports an experimental study on the standard molar enthalpies of formation, in the condensed phase, for three quinoxalinecarboxamide-1,4-dioxide derivatives, represented in Figure 1, and also of their respective enthalpies of phase transition.

Further, the first, second, and mean enthalpies of dissociation of the $\mathrm{N}-\mathrm{O}$ bonds in these compounds have been obtained from density functional theory calculations performed at the B3LYP/ 6-311+G(2d,2p)//B3LYP/6-31G(d) level of theory. This approach has been employed successfully in the past with an excellent agreement between computed and experimental results. ${ }^{10-12}$ Then, using the computed enthalpies for the reaction of dissociation of the two $\mathrm{N}-\mathrm{O}$ bonds together with the standard molar gas-phase enthalpies of formation of the oxygen atom and of compounds $\mathbf{1 a}-\mathbf{c}$, the enthalpy of formation of compounds $\mathbf{2} \mathbf{a}-\mathbf{c}$ were estimated.

\section{Experimental Section}

Materials: Synthesis and Characterization. Compound 1a was prepared by reacting benzofuroxan with acetoacetamide in the presence of ethanolamine and calcium chloride according to the published experimental method of Stumm and Niclas. ${ }^{14}$ The crude product was collected by vacuum filtration, washed with chilled methanol, and then purified by crystallization from anhydrous methanol. Compounds $\mathbf{1 b}$ and $\mathbf{c}$ were prepared in a similar fashion from acetoacetanilide and 2-methylacetoacetanilide, respectively. The crude products were crystallized from anhydrous methanol to give purified samples having observed melting temperatures in excellent agreement with published literature values. ${ }^{2}$ Elemental analyses were in excellent agreement with calculated values. Mass fraction for $\mathbf{1 a}, \mathrm{C}_{10} \mathrm{H}_{9} \mathrm{~N}_{3} \mathrm{O}_{3}$ : Found: C, 0.5470; H, 0.0426; N, 0.1911. Calcd: C, 0.5479; $\mathrm{H}, 0.0414 ; \mathrm{N}, 0.1917$. Mass fraction for $\mathbf{1 b}, \mathrm{C}_{16} \mathrm{H}_{13} \mathrm{~N}_{3} \mathrm{O}_{3}$ : 


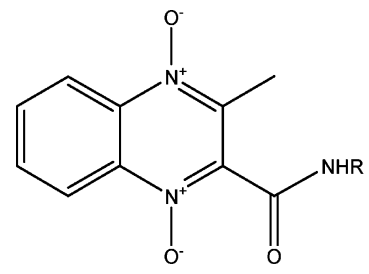

1

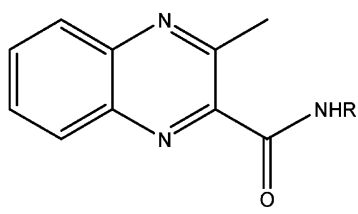

2
Figure 1. General structural formula of 3-methyl-quinoxaline-2- $N$-Rcarboxamide-1,4-dioxide and 3-methyl-quinoxaline-2- $\mathrm{N}$-R-carboxamide derivatives. $\mathrm{R}=\mathrm{H}$ : 3-methyl-2-quinoxalinecarboxamide-1,4-dioxide (1a); 3-methyl-2-quinoxalinecarboxamide (2a). R $=\mathrm{Ph}$ : 3-methyl- $N$ phenyl-2-quinoxalinecarboxamide-1,4-dioxide (1b); 3-methyl- $N$-phenyl2-quinoxalinecarboxamide (2b). $\mathrm{R}=o-\mathrm{CH}_{3} \mathrm{Ph}$ : 3-methyl- $\mathrm{N}$-(2methylphenyl)-2-quinoxalinecarboxamide-1,4-dioxide (1c); 3-methyl$N$-(2-methylphenyl)-2-quinoxalinecarboxamide (2c).

Found: C, 0.6491; H, 0.0448; N, 0.1420. Calcd: C, 0.6508; $\mathrm{H}, 0.0444 ; \mathrm{N}, 0.1423$. Mass fraction for 1c, $\mathrm{C}_{17} \mathrm{H}_{15} \mathrm{~N}_{3} \mathrm{O}_{3}$ : Found: C, 0.6622; H, 0.0484; N, 0.1356. Calcd: C, 0.6601; $\mathrm{H}, 0.0489 ; \mathrm{N}, 0.1358$.

Compound 1a was used immediately after its synthesis without additional purification. The composition of the compound was confirmed by the average ratio of the mass of carbon dioxide recovered after combustion experiments to that calculated from the mass of the sample $(0.9998 \pm 0.0006)$, and the differential scanning calorimetry (DSC) thermogram shows that there is no transition phase before the melting temperature (511 $\mathrm{K}$, with decomposition).

Compounds $\mathbf{1 b}$ and $\mathbf{c}$ were recrystallized from chloroform, dried under vacuum, and stored prior to usage. Compound $\mathbf{1 b}$ was seen to degrade during storage and was purified by column chromatography on silica, using dichloromethane/methanol (6:1 v/v) as eluant. The chromatographic separation allowed us to isolate two compounds that were both characterized by ${ }^{1} \mathrm{H}$ and ${ }^{13} \mathrm{C}$ NMR as well as by high-resolution mass spectrometry (MALDI-TOF). These compounds were identified as the desired quinoxaline-1,4-dioxide (1b) and its quinoxaline derivative (2b), according to spectroscopic data given separately as Supporting Information. After purification, compound $\mathbf{1 b}$ was used in the thermochemical studies, as detailed below. The average ratio of the mass of carbon dioxide recovered after combustion experiments to that calculated from the mass of samples (1b, $0.9971 \pm 0.0009$; 1c, $1.0005 \pm 0.0007)$ confirmed the purity of the samples. The thermal behavior of the compounds was studied by DSC. The thermograms show any transition phases before melting with decomposition (497 and $482 \mathrm{~K}$, respectively, for $\mathbf{1 b}$ and $\mathbf{c}$ ).

Unfortunately, the amount of isolated $\mathbf{2 b}$ was very small and, therefore, it was not possible to determine experimentally either its enthalpy of formation in the condensed phase or its enthalpy of phase transition.

Static Bomb Combustion Calorimetry. For each one of the three compounds, the energy of combustion was measured in a static bomb calorimeter, with a twin valve bomb and an internal volume of $0.290 \mathrm{dm}^{3}$, originally assembled in England ${ }^{15,16}$ and now installed in the Thermochemistry Laboratory at the University of Porto. ${ }^{17}$ The energy equivalent of the calorimeter was determined from the combustion of benzoic acid (BDH Thermochemical Standard, batch 693976/01) having a massic energy of combustion, under standard bomb conditions, of $-(26435.1 \pm 3.5) \mathrm{J} \cdot \mathrm{g}^{-1}$. The calibration results were corrected to an energy equivalent, $\epsilon$ (cal), corresponding to an average mass of water added to the calorimeter of $2900.0 \mathrm{~g}$. Seven calibration experiments were made in an oxygen atmosphere at $p=3.04$
$\mathrm{MPa}$, with $1.00 \mathrm{~cm}^{3}$ of water added to the bomb, leading to an energy equivalent of the calorimeter of $\epsilon$ (calor) $=15551.6 \pm$ $2.6 \mathrm{~J} \cdot \mathrm{K}^{-1}$, where the uncertainty quoted is the standard deviation of the mean.

The samples, in pellet form, were ignited in an oxygen atmosphere at $p=3.04 \mathrm{MPa}$, at $T=298.15 \mathrm{~K}$, and with 1.00 $\mathrm{cm}^{3}$ of water inside the bomb. The amounts available for the three compounds were small, so $n$-hexadecane was used as an auxiliary combustion material (standard massic energy of combustion, $\left.\Delta_{\mathrm{c}} u^{\circ}=-(47161.9 \pm 3.2) \mathrm{J} \cdot \mathrm{g}^{-1}\right)$ to produce the appropriate increase of temperature. For the cotton thread fuse of empirical formula $\mathrm{CH}_{1.686} \mathrm{O}_{0.843}, \Delta_{\mathrm{c}} u^{\circ}=-16250 \mathrm{~J} \cdot \mathrm{g}^{-1}{ }^{18}$ Corrections for nitric acid formation were based on -59.7 $\mathrm{kJ} \cdot \mathrm{mol}^{-1}$ for the molar energy of formation of $0.1 \mathrm{~mol} \cdot \mathrm{dm}^{3}$ $\mathrm{HNO}_{3}(\mathrm{aq})$ from $\mathrm{N}_{2}(\mathrm{~g}), \mathrm{O}_{2}(\mathrm{~g})$, and $\mathrm{H}_{2} \mathrm{O}(\mathrm{l}) .{ }^{19}$ At $T=298.15 \mathrm{~K}$, $(\partial u / \partial p)_{T}$ for the solid was assumed to be $-0.2 \mathrm{~J} \cdot \mathrm{g}^{-1} \cdot \mathrm{MPa}^{-1}$, a typical value for organic solids. The amount of compound burnt in each experiment was determined from the total mass of carbon dioxide produced after allowance for that resulted from the cotton thread fuse and $n$-hexadecane. For each experiment, the value of $\Delta_{\mathrm{c}} u^{\circ}$ was calculated by using the procedure given by Hubbard et al. ${ }^{20}$ The relative atomic masses used throughout this paper were those recommended by the IUPAC Commission in $2001 .^{21}$

Knudsen Effusion Experiments. The standard molar enthalpies of sublimation of the three of 3-methyl-quinoxaline2-carboxamide-1,4-dioxide derivatives were derived by the Knudsen effusion method, using the quartz microbalance previously described. ${ }^{22,23}$ The equipment was previously tested with benzanthrone, squaric acid, and 4-hydroxy-2-methylquinoline. ${ }^{23,24}$ During this work, the apparatus has also been tested with benzanthrone and 1,3,5-triphenylbenzene and the values obtained for their standard molar enthalpies of sublimation, $\Delta_{\mathrm{cr}}^{\mathrm{g}}$ $H_{\mathrm{m}}^{\circ}(298.15 \mathrm{~K})$, were $131.0 \pm 1.3$ and $150.3 \pm 2.6 \mathrm{~kJ} \cdot \mathrm{mol}^{-1}$, respectively. For comparison purposes, the values available in the literature are $129.7 \pm 2.1^{24}$ and $152.0 \pm 0.3 \mathrm{~kJ} \cdot \mathrm{mol}^{-1},{ }^{25}$ respectively. The vapor effusing from the Knudsen cell was allowed to condense on a quartz crystal positioned above the effusion hole; changes in the frequency, $\Delta f$, of oscillation of the quartz crystal were proportional to the mass condensed in its surface, ${ }^{26} \Delta f=C_{\mathrm{f}} \Delta m$, where $C_{\mathrm{f}}$ is a proportionally constant. From the Knudsen equation, the vapor pressure is given by eq 1 , where $(\Delta m / \Delta t)$ is the rate of mass loss, $a$ is the effective area of the effusion hole, and $M$ is the molar mass of the effusing vapor.

$$
p=(\Delta m / \Delta t) a^{-1}(2 \pi R T / M)^{1 / 2}
$$

As the measured rate of change of frequency of oscillation with time, $v=\Delta f / \Delta t$, is directly proportional to the rate of sublimed mass ${ }^{26}$ of the crystalline sample, $v=C_{\mathrm{f}} \Delta m / \Delta t$,

$$
p=v T^{1 / 2}(2 \pi R / M)^{1 / 2} /\left(a C_{\mathrm{f}}\right)
$$

By applying the integrated form of the Clausius-Clapeyron equation, the enthalpy of sublimation, $\Delta_{\mathrm{cr}}^{\mathrm{g}} H_{\mathrm{m}}^{\circ}$, is derived from the slope of $\ln \left(v T^{1 / 2}\right)$ against $T^{-1}$. From at least five independent sets of experimental measurements of the frequency of the quartz oscillator for each compound, at convenient temperature intervals, it was possible to obtain independent results for the enthalpy of sublimation of each compound, referred to the mean temperature of the experimental range.

Computational Details. Calculations were performed using the semiempirical B3LYP method, ${ }^{27}$ which uses the exchange functional introduced by Becke (mixture of exact Hartree-Fock 
TABLE 1: Typical Combustion Experiments for 3-Methyl-quinoxaline-2-carboxamide-1,4-dioxide Derivatives, at $T=298.15 \mathrm{~K}$

\begin{tabular}{llll}
\hline & \multicolumn{1}{c}{$\mathbf{1 a}$} & \multicolumn{1}{c}{$\mathbf{1 b}$} & \multicolumn{1}{c}{$\mathbf{1 c}$} \\
\hline$m\left(\mathrm{CO}_{2}\right.$, total $)(\mathrm{g})$ & 1.49375 & 1.70596 & 1.65354 \\
$m(\mathrm{cpd})(\mathrm{g})$ & 0.60657 & 0.58436 & 0.56152 \\
$m($ hexadecane $)(\mathrm{g})$ & 0.08678 & 0.09852 & 0.09311 \\
$m^{\prime}($ fuse) $)(\mathrm{g})$ & 0.00375 & 0.00380 & 0.00363 \\
$\Delta T_{\text {ad }}(\mathrm{K})$ & 1.17254 & 1.33442 & 1.311026 \\
$\epsilon_{\mathrm{f}}\left(\mathrm{J} \cdot \mathrm{K}^{-1}\right)$ & 14.32 & 14.44 & 14.45 \\
$\Delta m\left(\mathrm{H}_{2} \mathrm{O}\right)(\mathrm{g})$ & 2.00 & 1.30 & 1.30 \\
$-\Delta U(\mathrm{IBP})^{a}(\mathrm{~J})$ & 18261.53 & 20778.96 & 20402.77 \\
$\Delta U(\mathrm{HNO})(\mathrm{J})$ & 48.95 & 39.40 & 39.40 \\
$\Delta U($ ign $)(\mathrm{J})$ & 1.13 & 0.68 & 1.07 \\
$\Delta U_{\Sigma}(\mathrm{J})$ & 13.27 & 13.33 & 12.74 \\
$\Delta U($ hexadecane $)(\mathrm{J})$ & 4092.59 & 4646.49 & 4391.02 \\
$\Delta U($ fuse $)(\mathrm{J})$ & 60.90 & 61.71 & 58.95 \\
$-\Delta_{\mathrm{c}} u^{\circ}\left(\mathrm{J} \cdot \mathrm{g}^{-1}\right)$ & 23154.34 & 27410.18 & 28315.48 \\
${ }^{a} \Delta U(\mathrm{IBP})$ already includes $\Delta U($ ign $)$. & & \\
\end{tabular}

and Slater local-density exchange added by a correction term) and the LYP correlation functional of Lee et al. ${ }^{28,29}$ as included in the Gaussian 03 computer code. ${ }^{30}$ The atomic electron density of hydrogen, carbon, nitrogen, and oxygen atoms has been described by means of the $6-31 \mathrm{G}(\mathrm{d})$ and $6-311+\mathrm{G}(2 \mathrm{~d}, 2 \mathrm{p})$ basis sets. The former basis has been used to fully optimize the geometry of all compounds and to compute the vibrational frequencies. The absence of negative frequencies ensured that all structures were minima on the potential energy surface. The larger basis set was used only for the full optimization of the structures of all compounds. Finally, the enthalpies of all compounds were obtained by combining the energy coming from the full optimizations completed at the highest level of theory and the thermal corrections retrieved from the scaled vibrational frequency (factor $=0.98$ ) calculations performed at the B3LYP/ 6-31G(d) level. From now on, this computational strategy is referred as B3LYP/6-311+G(2d,2p)//B3LYP/6-31G(d).

\section{Results and Discussion}

Gas-Phase Enthalpies of Formation for $\mathbf{1 a}-\mathbf{c}$. The standard gas-phase enthalpy of formation, $T=298.15 \mathrm{~K}$, of each of the 3-methyl-quinoxaline-2-carboxamide-1,4-dioxide derivatives was calculated by combination of the enthalpy of formation with the enthalpy of sublimation of the crystal, determined by isoperibol static bomb calorimetry and the Knudsen effusion method, respectively. Typical results for one combustion experiment of each compound are presented in Table 1. The samples were ignited at $T=298.15 \mathrm{~K}$, so the energy involved in the isothermal bomb process, $\Delta U(\mathrm{IBP})$, is derived from eq 3 , where $\Delta T_{\mathrm{ad}}$ is the calorimeter temperature change corrected for heat exchange and the work of stirring, $\Delta m\left(\mathrm{H}_{2} \mathrm{O}\right)$ is the deviation of the mass of water added to the calorimeter from $2900.0 \mathrm{~g}$ (the mass assigned for $\epsilon$ (calor)), $\Delta U_{\Sigma}$ is the correction to the standard state, and the remaining terms were previously described. ${ }^{20}$

$$
\begin{array}{r}
\Delta U(\mathrm{IBP})=-\left\{\epsilon(\text { calor })+c_{p}\left(\mathrm{H}_{2} \mathrm{O}, 1\right) \Delta m\left(\mathrm{H}_{2} \mathrm{O}\right)+\epsilon_{\mathrm{f}}\right\} \Delta T_{\mathrm{ad}}+ \\
\Delta U(\mathrm{ign})(3)
\end{array}
$$

The mean value of massic energy of combustion, $\Delta_{\mathrm{c}} u^{\circ}$, of the crystalline compound, at $T=298.15 \mathrm{~K}$, has been used to calculate the corresponding values of the standard molar energy of combustion, $\Delta_{\mathrm{c}} U_{\mathrm{m}}^{\circ}(\mathrm{cr})$, and the standard molar enthalpy of combustion, $\Delta_{\mathrm{f}} H_{\mathrm{m}}^{\circ}(\mathrm{cr})$; this last value and the values for the standard molar enthalpies of formation taken from the literature ${ }^{31}$ for $\mathrm{H}_{2} \mathrm{O}(\mathrm{l})$ and for $\mathrm{CO}_{2}(\mathrm{~g}),-(285.83 \pm 0.04)$ and $-(393.51 \pm$ $0.13) \mathrm{kJ} \cdot \mathrm{mol}^{-1}$, respectively, allow the standard molar enthalpy
TABLE 2: Derived Standard $\left(p^{\circ}=0.1 \mathrm{MPa}\right)$ Molar Energies of Combustion, $\Delta_{\mathrm{c}} U_{\mathrm{m}}^{\circ}$, Standard Molar Enthalpies of Combustion, $\boldsymbol{\Delta}_{\mathrm{c}} H_{\mathrm{m}}^{\circ}$, and Standard Molar Enthalpies of Formation, $\boldsymbol{\Delta}_{\mathrm{f}} H_{\mathrm{m}}^{\circ}$, for Crystalline Compounds $1 \mathrm{a}-\mathbf{c}$, at $\boldsymbol{T}=$ 298.15 K

\begin{tabular}{lccccr}
\hline & \multicolumn{1}{c}{$\begin{array}{c}-\Delta_{\mathrm{c}} u^{\circ} \\
\left(\mathrm{J} \cdot \mathrm{g}^{-1}\right)\end{array}$} & $\begin{array}{c}-\Delta_{\mathrm{c}} U_{\mathrm{m}}^{\circ}(\mathrm{cr}) \\
\left(\mathrm{kJ} \cdot \mathrm{mol}^{-1}\right)\end{array}$ & $\begin{array}{c}-\Delta_{\mathrm{c}} H_{\mathrm{m}}^{\circ}(\mathrm{cr}) \\
\left(\mathrm{kJ} \cdot \mathrm{mol}^{-1}\right)\end{array}$ & $\begin{array}{c}\Delta_{\mathrm{f}} H_{\mathrm{m}}^{\circ}(\mathrm{cr}) \\
\left(\mathrm{kJ} \cdot \mathrm{mol}^{-1}\right)\end{array}$ \\
\hline 1a & $23158.1 \pm 7.8$ & $5076.2 \pm 3.9$ & $5074.4 \pm 3.9$ & $-146.9 \pm 4.1$ \\
1b & $27415.8 \pm 11.5$ & $8095.8 \pm 7.4$ & $8096.4 \pm 7.4$ & $-57.6 \pm 7.7$ \\
1c & $28320.0 \pm 6.0$ & $8760.0 \pm 4.9$ & $8761.9 \pm 4.9$ & $-71.5 \pm 5.4$
\end{tabular}

of formation for crystalline compound, $\Delta_{\mathrm{f}} H_{\mathrm{m}}^{\circ}(\mathrm{cr})$, to be derived. In Table 2, a summary of the final results for these parameters derived for the three compounds is presented.

The results for the measurement of the standard molar enthalpies of sublimation of $\mathbf{1 a}-\mathbf{c}$, by the Knudsen method, are summarized in Tables 3-5, respectively, together with the mean temperatures of the experimental ranges and the standard molar enthalpies of sublimation at these mean temperatures, $\Delta_{\mathrm{cr}}^{\mathrm{g}} H_{\mathrm{m}}^{\circ}(\langle T\rangle)$; the parameter of the Clausius-Clapeyron equation corresponding to the slope was obtained using a leastsquares fitting of the experimental data. The value of $\Delta_{\mathrm{cr}}^{\mathrm{g}} H_{\mathrm{m}}^{\circ}$ $(\langle T\rangle)$ was corrected to $T=298.15 \mathrm{~K}$ assuming $\Delta_{\mathrm{cr}}^{\mathrm{g}} C_{p, \mathrm{~m}}^{\circ}=-50$ $\mathrm{J} \cdot \mathrm{K}^{-1} \cdot \mathrm{mol}^{-1},{ }^{22}$ yielding the final $\Delta_{\mathrm{cr}}^{\mathrm{g}} H_{\mathrm{m}}^{\circ}$ value. The uncertainties assigned are twice the overall standard deviations of the mean.

The enthalpies of formation of compounds $\mathbf{1 a}-\mathbf{c}$ were obtained from the corresponding standard enthalpies of formation in the crystalline state and from their enthalpies of sublimation. The final standard molar enthalpies of formation, in both crystalline and gaseous states, as well as the standard molar enthalpies of sublimation, at $T=298.15 \mathrm{~K}$, for the compounds studied in this work are summarized in Table 6.

The present computational approach was found previously to be suitable for the estimation of standard gas-phase enthalpies of formation if it was used in conjugation with a working reaction embracing structurally similar reactants and products for which accurate experimental enthalpies of formation are already known. ${ }^{10,12,32-35}$ Here, the use of this computational approach is quite difficult, since the experimental enthalpies of formation for key species, such as $\mathrm{C}_{6} \mathrm{H}_{5} \mathrm{~N}(-\mathrm{H}) \mathrm{C}(=\mathrm{O})-\mathrm{X}$, where $\mathrm{X}$ is a methyl group or, even more interesting, an aromatic ring, are not available in the literature. Therefore, from our experience, large errors are to be expected if the present computational approach is used to estimate the gas-phase enthalpies of formation for compounds $\mathbf{1 b}$ and $\mathbf{c}$ without the knowledge of thermochemical data for similar compounds. In the case of compound 1a, it is possible to estimate its enthalpy of formation in the gas phase considering the following working reaction:<smiles>Cc1cnccn1</smiles> 
TABLE 3: Parameters of the Clausius-Clapeyron Equation and Standard Enthalpies of Sublimation for 1a

\begin{tabular}{cccccccc}
\hline $\mathrm{n}^{\circ} \exp$ & $T(\mathrm{~K})$ & $\langle T\rangle(\mathrm{K})$ & $a(\mathrm{~K})$ & $-b$ & $r$ & $\Delta_{\mathrm{cr}}^{\mathrm{g}} H_{\mathrm{m}}^{\circ}(\langle T\rangle)\left(\mathrm{kJ} \cdot \mathrm{mol}^{-1}\right)$ & $\Delta_{\mathrm{cr}}^{\mathrm{g}} H_{\mathrm{m}}^{\circ}(298.15 \mathrm{~K})\left(\mathrm{kJ} \cdot \mathrm{mol}^{-1}\right)$ \\
\hline 1 & $421.1-436.2$ & 428.7 & $43.33 \pm 0.41$ & $18357 \pm 175$ & 0.9998 & 152.6 & 158.9 \\
2 & $421.6-436.7$ & 429.2 & $46.33 \pm 0.30$ & $19658 \pm 127$ & 0.9999 & 162.3 & 168.6 \\
3 & $425.2-437.2$ & 431.2 & $45.49 \pm 1.16$ & $19047 \pm 494$ & 0.9990 & 158.4 & 164.8 \\
4 & $417.7-432.7$ & 425.2 & $47.80 \pm 0.92$ & $20057 \pm 389$ & 0.9992 & 166.7 & 172.9 \\
5 & $425.1-432.2$ & 430.2 & $44.69 \pm 1.06$ & $19000 \pm 451$ & 0.9992 & 158.0 & 168.3 \\
6 & $425.6-438.2$ & 432.7 & $47.68 \pm 0.69$ & $20255 \pm 295$ & 0.9997 & 168.4 & 174.9 \\
7 & $430.9-441.3$ & 436.2 & $43.84 \pm 0.54$ & $18798 \pm 232$ & 0.9998 & 156.3 & 162.9 \\
8 & $428.1-440.7$ & 434.4 & $44.59 \pm 1.01$ & $19162 \pm 433$ & 0.9990 & 159.3 & 165.9 \\
& & \multicolumn{7}{c}{$\Delta_{\mathrm{cr}}^{\mathrm{g}} H_{\mathrm{m}}^{\circ}(298.15 \mathrm{~K})=166.6 \pm 3.7 \mathrm{~kJ}^{2} \cdot \mathrm{mol}^{-1}$} &
\end{tabular}

TABLE 4: Parameters of the Clausius-Clapeyron Equation and Standard Enthalpies of Sublimation for 1b

\begin{tabular}{cccccccc}
\hline $\mathrm{n}^{\circ} \exp$ & $T(\mathrm{~K})$ & $\langle T\rangle(\mathrm{K})$ & $a(\mathrm{~K})$ & $-b$ & $r$ & $\Delta_{\mathrm{cr}}^{\mathrm{g}} H_{\mathrm{m}}^{\circ}(\langle T\rangle)\left(\mathrm{kJ} \cdot \mathrm{mol}^{-1}\right)$ & $\Delta_{\mathrm{cr}}^{\mathrm{g}} H_{\mathrm{m}}^{\circ}(298.15 \mathrm{~K})\left(\mathrm{kJ} \cdot \mathrm{mol}^{-1}\right)$ \\
\hline 1 & $409.1-421.1$ & 415.2 & $40.02 \pm 1.36$ & $16815 \pm 566$ & 0.9989 & 139.8 & 145.7 \\
2 & $406.1-421.2$ & 413.7 & $39.83 \pm 0.53$ & $16746 \pm 218$ & 0.9997 & 139.2 & 145.0 \\
3 & $406.1-418.1$ & 412.2 & $36.11 \pm 1.78$ & $15355 \pm 735$ & 0.9966 & 127.6 & 133.4 \\
4 & $412.1-427.1$ & 419.7 & $39.24 \pm 1.39$ & $16302 \pm 584$ & 0.9974 & 136.5 & 141.6 \\
5 & $406.2-418.0$ & 412.2 & $43.67 \pm 1.06$ & $17887 \pm 436$ & 0.9991 & 148.7 & 154.4 \\
6 & $404.1-416.2$ & 410.3 & $39.83 \pm 1.08$ & $16399 \pm 443$ & 0.9982 & 136.3 & 141.9 \\
7 & $408.0-419.7$ & 414.1 & $43.44 \pm 1.31$ & $17831 \pm 542$ & 0.9986 & 148.2 & 154.0 \\
\multicolumn{7}{c}{$\Delta_{\mathrm{cr}}^{\mathrm{g}} H_{\mathrm{m}}^{\circ}(298.15 \mathrm{~K})=145.1 \pm 5.6 \mathrm{~kJ} \cdot \mathrm{mol}^{-1}$} &
\end{tabular}

TABLE 5: Parameters of the Clausius-Clapeyron Equation and Standard Enthalpies of Sublimation for 1c

\begin{tabular}{cccccccc}
\hline $\mathrm{n}^{\circ} \exp$ & $T(\mathrm{~K})$ & $\langle T\rangle(\mathrm{K})$ & $a(\mathrm{~K})$ & $-b$ & $r$ & $\Delta_{\mathrm{cr}}^{\mathrm{g}} H_{\mathrm{m}}^{\circ}(\langle T\rangle)\left(\mathrm{kJ} \cdot \mathrm{mol}^{-1}\right)$ & $\Delta_{\mathrm{cr}}^{\mathrm{g}} H_{\mathrm{m}}^{\circ}(298.15 \mathrm{~K})\left(\mathrm{kJ} \cdot \mathrm{mol}{ }^{-1}\right)$ \\
\hline 1 & $408.5-421.3$ & 415.7 & $44.19 \pm 0.23$ & $18383 \pm 95$ & 0.9999 & 152.8 & 158.4 \\
2 & $408.4-421.1$ & 415.6 & $42.82 \pm 0.85$ & $17859 \pm 350$ & 0.9994 & 148.5 & 154.1 \\
3 & $410.6-420.7$ & 415.7 & $42.05 \pm 1.14$ & $17538 \pm 469$ & 0.9989 & 145.8 & 151.4 \\
4 & $410.6-423.1$ & 416.9 & $43.95 \pm 0.76$ & $18343 \pm 314$ & 0.9994 & 152.5 & 158.2 \\
5 & $410.1-422.6$ & 416.4 & $42.16 \pm 0.93$ & $17562 \pm 384$ & 0.9990 & 146.0 & 151.7 \\
\multicolumn{7}{c}{$\Delta_{\mathrm{cr}}^{\mathrm{g}} H_{\mathrm{m}}^{\circ}(298.15 \mathrm{~K})=154.8 \pm 3.0 \mathrm{~kJ} \cdot \mathrm{mol}^{-1}$} \\
\end{tabular}

TABLE 6: Derived Standard $\left(p^{\circ}=0.1\right.$ MPa $)$ Molar Enthalpies of Formation, $\Delta_{\mathrm{f}} H_{\mathrm{m}}^{\circ}$, and Standard Molar Enthalpies of Sublimation, $\Delta_{\mathrm{cr}}^{\mathrm{g}} H_{\mathrm{m}}^{\circ}$, for

3-Methyl-quinoxaline-2-carboxamide-1,4-dioxide Derivatives, at $T=298.15 \mathrm{~K}$

\begin{tabular}{cccc}
\hline & $\begin{array}{c}\Delta_{\mathrm{f}} H_{\mathrm{m}}^{\circ}(\mathrm{cr}) \\
\left(\mathrm{kJ} \cdot \mathrm{mol}^{-1}\right)\end{array}$ & $\begin{array}{c}\Delta_{\mathrm{cr}}^{\mathrm{g}} H_{\mathrm{m}}^{\circ} \\
\left(\mathrm{kJ} \cdot \mathrm{mol}^{-1}\right)\end{array}$ & $\begin{array}{c}\Delta_{\mathrm{f}} H_{\mathrm{m}}^{\circ}(\mathrm{g}) \\
\left(\mathrm{kJ} \cdot \mathrm{mol}^{-1}\right)\end{array}$ \\
\hline $\mathbf{1 a}$ & $-146.9 \pm 4.1$ & $166.6 \pm 3.7$ & $19.7 \pm 5.5$ \\
$\mathbf{1 b}$ & $-57.6 \pm 7.7$ & $145.1 \pm 5.6$ & $87.5 \pm 9.5$ \\
$\mathbf{1 c}$ & $-71.5 \pm 5.4$ & $154.8 \pm 3.0$ & $83.3 \pm 6.2$
\end{tabular}

The gas-phase enthalpies of formation of 2,3-dimethyl-quinoxaline-1,4-dioxide and of pyrazinamide are known from the literature with values of $\Delta_{\mathrm{f}} H_{\mathrm{m}}^{\circ}(\mathrm{g})=149.4 \pm 4.5 \mathrm{~kJ} \cdot \mathrm{mol}^{-1} 10$ and $\Delta_{\mathrm{f}} H_{\mathrm{m}}^{\circ}(\mathrm{g})=8.5 \pm 2.6 \mathrm{~kJ} \cdot \mathrm{mol}^{-1},{ }^{36}$ respectively. The $\Delta_{\mathrm{f}} H_{\mathrm{m}}^{\circ}(\mathrm{g})$ value for methylpyrazine is not known, but it can be estimated from G3MP2//B3LYP calculations (G3MP2B3 keyword in Gaussian 03) and the atomization reaction. This computational strategy must be used with caution, since it is known that it can give erroneous estimates for relatively large compounds; the molecular size of methylpyrazine is acceptable, since the tuning of the above-mentioned composite approach included some compounds with sizes relatively similar to that of methylpyrazine. Anyway, we have tested the G3MP2// B3LYP/atomization reaction strategy for a quite similar compound, ethylpyrazine, for which the $\Delta_{\mathrm{f}} H_{\mathrm{m}}^{\circ}(\mathrm{g})$ value is available in the literature; ${ }^{37}$ the experimental standard enthalpy of formation in the gas phase for the latter compound is $146.9 \pm$ $2.8 \mathrm{~kJ} \cdot \mathrm{mol}^{-1}$. ${ }^{37}$ The G3MP2//B3LYP estimated value is 140.7 $\mathrm{kJ} \cdot \mathrm{mol}^{-1}$, which is in good agreement with the experimental result. Therefore, one should expect that the same approach will be reliable for a slightly smaller but identical species. For the methylpyrazine compound, the G3MP2//B3LYP $\Delta_{\mathrm{f}} H_{\mathrm{m}}^{\circ}(\mathrm{g})$ value is $161.8 \mathrm{~kJ} \cdot \mathrm{mol}^{-1}$. Using the three gas-phase enthalpies of formation and the B3LYP/6-311+G(2d,2p)//B3LYP/6-31G(d) computed enthalpy for the reaction described by eq 4 , which is $-20.4 \mathrm{~kJ} \cdot \mathrm{mol}^{-1}$, it comes that the estimated enthalpy of formation for compound $\mathbf{1 a}$ is $16.5 \mathrm{~kJ} \cdot \mathrm{mol}^{-1}$, which is in excellent agreement with the experimental result pointed out in the preceding section, that is, $\Delta_{\mathrm{f}} H_{\mathrm{m}}^{\circ}(\mathrm{g})=19.7 \pm 5.5$ $\mathrm{kJ} \cdot \mathrm{mol}^{-1}$. In fact, the estimated result lies inside the interval of values defined by the uncertainty associated with the experimental $\Delta_{\mathrm{f}} H_{\mathrm{m}}^{\circ}(\mathrm{g})$ value for compound 1a. This reinforces the idea that the present density functional theory (DFT) strategy is adequate for the calculation of thermochemical data regarding quinoxaline derivatives.

N-O Bond Dissociation Enthalpies. The compounds studied in the present work have two different $\mathrm{N}-\mathrm{O}$ bonds, one closer to the methyl group and the other closer to the carboxamide substituent, and therefore, due to the different chemical neighborhoods, these bonds are expected to have different strengths. Thus, these bonds are cleaved at different energies and we may introduce the terms (i) first $\mathrm{N}-\mathrm{O}$ bond dissociation enthalpy, which is associated with the energy required to break the weakest bond in the di- $N$-oxide compound yielding the corresponding $\mathrm{N}$-oxide, (ii) second $\mathrm{N}-\mathrm{O}$ bond dissociation enthalpy, which is related to the energy required to break the bond in the $\mathrm{N}$-oxide compound yielding the parent quinoxaline compound, and, finally, (iii) the mean $\mathrm{N}-\mathrm{O}$ bond dissociation enthalpy that is connected with the sum of the former two dissociation enthalpies divided by 2 . This notation has also been used in previous works. ${ }^{10-13,38}$

The B3LYP/6-311+G(2d,2p)//B3LYP/6-31G(d) computed dissociation enthalpies for $\mathbf{1 a}$ are reported in Figure 2. The enthalpies computed for the removal of a single oxygen atom from compound 1a show that the weakest bond is that nearby the carboxamide group. The enthalpy required to cleave this bond is $241.7 \mathrm{~kJ} \cdot \mathrm{mol}^{-1}$, approximately $10 \mathrm{~kJ} \cdot \mathrm{mol}^{-1}$ lower than 


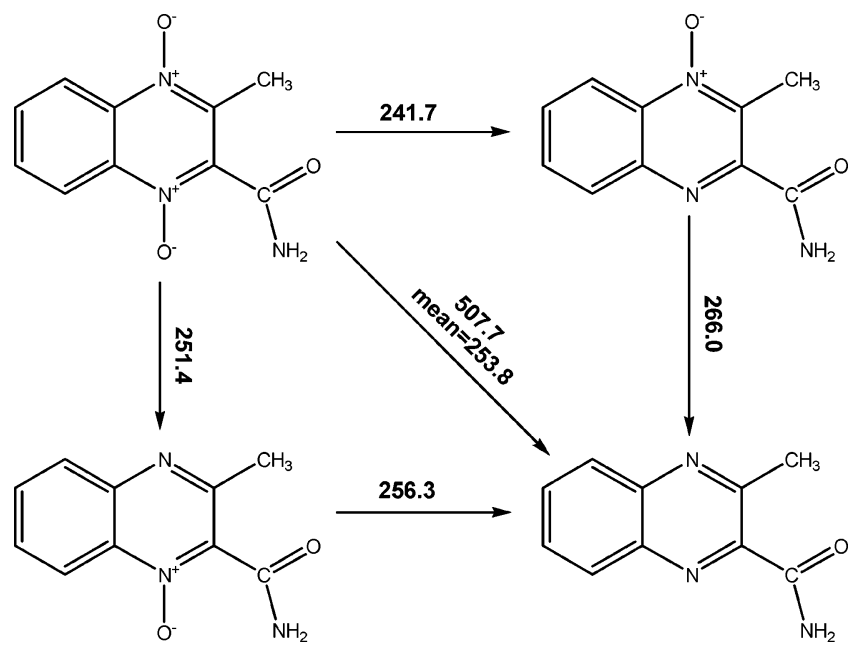

Figure 2. First, second, and mean $\mathrm{N}-\mathrm{O}$ bond dissociation enthalpies for compound 1a.

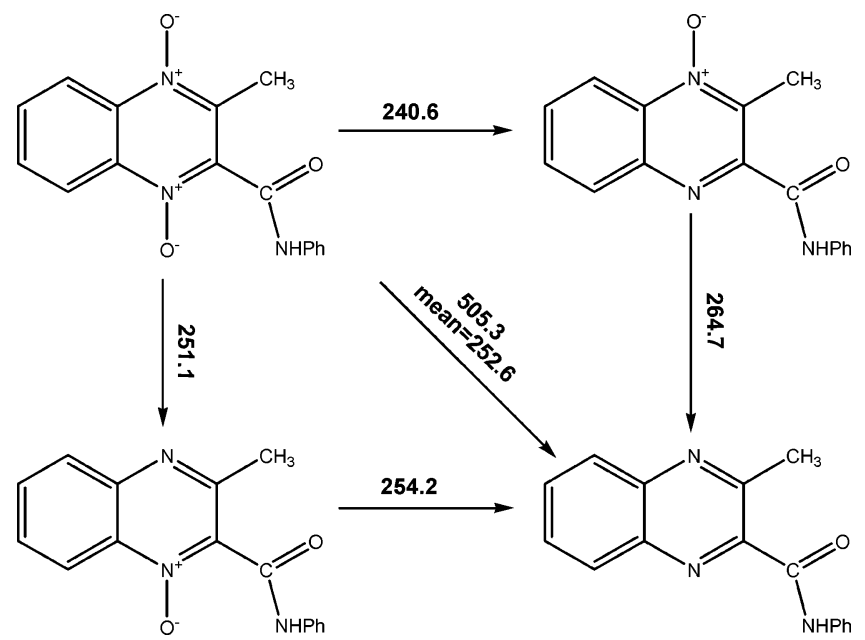

Figure 3. First, second, and mean $\mathrm{N}-\mathrm{O}$ bond dissociation enthalpies for compound $\mathbf{1 b}$.

that required to remove the oxygen atom closer to the methyl substituent. The computed second $\mathrm{N}-\mathrm{O}$ bond dissociation enthalpy is $266.0 \mathrm{~kJ} \cdot \mathrm{mol}^{-1}$. The absolute enthalpy required to remove both oxygen atoms from compound $\mathbf{1 a}$ yielding $\mathbf{2 a}$ is $507.7 \mathrm{~kJ} \cdot \mathrm{mol}^{-1}$; that is, the mean $\mathrm{N}-\mathrm{O}$ bond dissociation enthalpy is $253.8 \mathrm{~kJ} \cdot \mathrm{mol}^{-1}$.

In the case of compounds $\mathbf{1 b}$ and $\mathbf{c}$, the first bond to be cleaved is also that closer to the carboxamide group; compare Figures 3 and 4. For the former compound, the first, second, and mean $\mathrm{N}-\mathrm{O}$ bond dissociation enthalpies are 240.6, 264.7, and $252.6 \mathrm{~kJ} \cdot \mathrm{mol}^{-1}$, respectively, while, for the latter, they are $240.3,265.0$, and $252.6 \mathrm{~kJ} \cdot \mathrm{mol}^{-1}$, respectively.

Interestingly, since the enthalpies computed for compounds $\mathbf{1 b}$ and $\mathbf{c}$ are similar to that computed for species 1a, the consideration of a much larger substituent in $\mathbf{1 b}$ did not introduce any significant steric influence in any of the $\mathrm{N}-\mathrm{O}$ bonds. This is a very important point, since it suggests that the consideration of bulky groups that are not bonded directly to the quinoxaline rings seem to not significantly affect the $\mathrm{N}-\mathrm{O}$ bonds and, consequently, such groups do not reduce the enthalpy required to cleave these bonds. The last sentence is also in agreement with the identical first, second, and mean $\mathrm{N}-\mathrm{O}$ bond dissociation enthalpies found previously for a similar compound, namely, 3-methyl-2-ethoxycarbonyl-quinoxaline-1,3-dioxide. ${ }^{10}$

Gas-Phase Enthalpies of Formation for $\mathbf{2 a}-\mathbf{c}$. As already shown above, the present computational approach is suitable

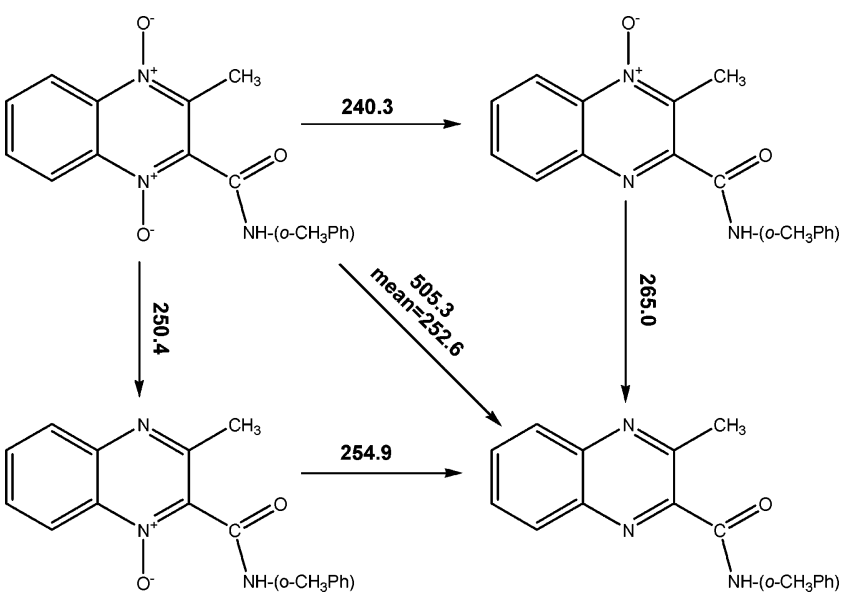

Figure 4. First, second, and mean $\mathrm{N}-\mathrm{O}$ bond dissociation enthalpies for compound $1 \mathbf{c}$.

for the estimation of standard gas-phase enthalpies of formation if a working reaction dealing with similar compounds in both reactants and products is used. Further, the same DFT methodology yields accurate $\mathrm{N}-\mathrm{O}$ bond dissociation enthalpies for this class of compounds. Therefore, it is possible to estimate the standard enthalpies of formation for compounds $\mathbf{2 a}-\mathbf{c}$ by considering the experimental $\Delta_{\mathrm{f}} H_{\mathrm{m}}^{\circ}(\mathrm{g})$ values for compounds $1 \mathbf{a}-\mathbf{c}$, see Table 6 , and atomic oxygen, $\Delta_{\mathrm{f}} H_{\mathrm{m}}^{\circ}(\mathrm{O}, \mathrm{g})=249.18$ $\pm 0.10 \mathrm{~kJ} \cdot \mathrm{mol}^{-1},{ }^{31}$ and the computed enthalpies for reactions of double $\mathrm{N}-\mathrm{O}$ dissociation (diagonal arrow) shown in Figures 2-4. The estimates are $29.0 \mathrm{~kJ} \cdot \mathrm{mol}^{-1}$ for compound $\mathbf{2 a}, 94.4$ $\mathrm{kJ} \cdot \mathrm{mol}^{-1}$ for compound $\mathbf{2 b}$, and $90.2 \mathrm{~kJ} \cdot \mathrm{mol}^{-1}$ for compound 2c.

The gas-phase enthalpy of formation for compound $\mathbf{2 a}$ can also be estimated in a similar way to that employed above for compound 1a, that is, considering a reaction identical to that described by eq 4 but with the quinoxaline derivatives instead of the quinoxaline-1,4-dioxide ones.<smiles>Cc1cnccn1</smiles>

The enthalpy of the reaction described by eq 5 is $-7.1 \mathrm{~kJ} \cdot \mathrm{mol}^{-1}$. Then, using the experimental standard enthalpy of formation for 2,3-dimethyl-quinoxaline, $\Delta_{\mathrm{f}} H_{\mathrm{m}}^{\circ}(\mathrm{g})=172.9 \pm 3.0$ $\mathrm{kJ} \cdot \mathrm{mol}^{-1}, 39$ the estimated value for compound $\mathbf{2 a}$ is now 20.5 $\mathrm{kJ} \cdot \mathrm{mol}^{-1}$. This value is $8.5 \mathrm{~kJ} \cdot \mathrm{mol}^{-1}$ lower than the estimate coming from the use of the reaction for double $\mathrm{N}-\mathrm{O}$ bond dissociation of 1a depicted by the diagonal arrow in Figure 2. Considering the fact that the estimate for compound 1a was smaller than the experimental result here reported, the same rationale led us to conclude that the best estimate would be comprised between the value coming from the use of the double $\mathrm{N}-\mathrm{O}$ bond dissociation reaction and that coming from the use of eq 5 . 


\section{Conclusions}

In the present work, the combination of two different techniques, namely, static bomb combustion calorimetry and the Knudsen effusion technique, allowed the measurement of the standard molar energies of combustion and the enthalpies of sublimation, respectively, of three 3-methyl- $N$-R-2-quinoxalinecarboxamide-1,4-dioxide derivatives, with $\mathrm{R}=\mathrm{H}$, phenyl, and 2-tolyl. From these quantities, it was then possible to determine, for each of these compounds, the standard molar enthalpies of formation in the condensed and gaseous phases.

The standard molar enthalpy of formation in the gas phase of the smaller quinoxaline-1,4-dioxide, that is, with $\mathrm{R}=\mathrm{H}$, was compared with that estimated by density functional theory. The comparison was found to be rather good, and since it was found previously that the B3LYP/6-311+G(2d,2p)//B3LYP/6-31G(d) approach was suitable for the estimation of thermochemical parameters for other quinoxaline-1,4-dioxides, the same methodology has been employed here to estimate the following quantities: standard gas-phase enthalpies of formation of the 3-methyl- $N$-R-2-quinoxalinecarboxamides, the first and mean $\mathrm{N}-\mathrm{O}$ bond dissociation enthalpies of the three 3-methyl- $N$-R2-quinoxalinecarboxamide-1,4-dioxides, and, finally, the $\mathrm{N}-\mathrm{O}$ bond dissociation enthalpies in the 3-methyl- $N$-R-2-quinoxalinecarboxamide-1-oxides or in the 2-methyl- $N$-R-3-quinoxalinecarboxamide-1-oxides.

The comparison of the enthalpies of dissociation computed for the three quinoxaline derivatives studied here seems to suggest that the size of the groups introduced at positions 2 and 3 , that is, at carbon atoms adjacent to the $\mathrm{N}-\mathrm{O}$ bonds, negligibly affects these bonds. Further, comparison with previous works dealing with quinoxaline-1,4-dioxides seem to indicate that the strength of the $\mathrm{N}-\mathrm{O}$ bonds is only dictated by the type, rather than the size, of the group directly bonded to the quinoxaline ring.

Acknowledgment. Thanks are due to Fundação para a Ciência e Tecnologia for financial support to Centro de Investigação em Química and for the project POCTI(44471/ QUI/2002). E.A.S. and J.R.B.G. acknowledge the research grants SFRH/BD/5355/2001 and SFRH/BPD/24676/2005, respectively.

Supporting Information Available: NMR data for compounds $\mathbf{1 b}$ and $\mathbf{2 b}$ and optimized geometries (Cartesian coordinates) and energetic data for all compounds. This material is available free of charge via the Internet at http://pubs.acs.org.

\section{References and Notes}

(1) Ortega, M. A.; Morancho, M. J.; Martínez-Crespo, F. J.; Sainz, Y.; Montoya, M. E.; Ceráin, A. L.; Monge, A. Eur. J. Med. Chem. 2000, $35,21$.

(2) Zarranz, B.; Jaso, A.; Aldana, I.; Monge, A. Bioorg. Med. Chem. 2003, 11, 2149 .

(3) Mateu, M.; Capilla, A. S.; Harrak, Y.; Pujol, M. D. Tetrahedron 2002, 58,5241 .

(4) Indira Priyadarsini, K.; Dennis, M. F.; Naylor, M. A.; Stratford, M. R. L.; Wadman, P. J. Am. Chem. Soc. 1996, 118, 5648.

(5) Inbaraj, J. J.; Motten, A. G.; Chignell, C. F. Chem. Res. Toxicol. 2003, 16, 164

(6) Jaso, A.; Zarranz, B.; Aldana, I.; Monge, A. J. Med. Chem. 2005, 48, 2019.

(7) Waring, M. J.; Ben-Hadda, T.; Kotchevar, A. T.; Ramdani, A.; Touzani, R.; Elkadiri, S.; Hakkou, A.; Bouakka, M.; Ellis, T. Molecules 2002, 7, 641.

(8) Ganley, B.; Chowdhury, G.; Bhansali, J.; Daniels, J. S.; Gates, K. S. Bioorg. Med. Chem. 2001, 9, 2395.
(9) Acree, W. E., Jr.; Powell, J. R.; Tucker, S. A.; Ribeiro da Silva, M. D. M. C.; Matos, M. A. R. Gonçalves, J. M.; Santos, L. M. N. B. F.; Morais, V. M. F.; Pilcher, G. J. Org. Chem. 1997, 62, 3722.

(10) Ribeiro da Silva, M. D. M. C.; Gomes, J. R. B.; Gonçalves, J. M.; Sousa, E. A.; Pandey, S.; Acree, W. E., Jr. J. Org. Chem. 2004, 69, 2785.

(11) Ribeiro da Silva, M. D. M. C.; Gomes, J. R. B.; Gonçalves, J. M.; Sousa, E. A.; Pandey, S.; Acree, W. E., Jr. Org. Biomol. Chem. 2004, 2, 2507.

(12) Gomes, J. R. B.; Sousa, E. A.; Gonçalves, J. M.; Monte, M. J. S.; Gomes, P.; Pandey, S.; Acree, W. E., Jr.; Ribeiro da Silva, M. D. M. C. J. Phys. Chem. B 2005, 109, 16188.

(13) Gomes, J. R. B.; Ribeiro da Silva, M. D. M. C.; Ribeiro da Silva, M. A. V. Chem. Phys. Lett. 2006, 429, 18.

(14) Stumm, G.; Niclas, H. J. J. Prakt. Chem. (Leipzig) 1989, 331, 736.

(15) Gundry, H. A.; Harrop, D.; Head, A. J.; Lewis, G. B. J. Chem. Thermodyn. 1969, 1, 321.

(16) Bickerton, J.; Pilcher, G.; Al-Taklin, G. J. Chem. Thermodyn. 1984, $16,373$.

(17) Ribeiro da Silva, M. D. M. C.; Santos, L. M. N. B. F.; Silva, A. L. R.; Fernandes, O.; Acree, W. E., Jr. J. Chem. Thermodyn. 2003, 35, 1093.

(18) Coops, J.; Jessup, R. S.; Van Nes, K. In Experimental Thermochemistry; Rossini, F. D., Ed.; Interscience: New York, 1956; Vol. 1, Chapter 3.

(19) The NBS Tables of Chemical Thermodynamic Properties, J. Phys. Chem. Ref. Data 1982, II, Supplement No. 2.

(20) Hubbard, W. N.; Scott, D. W.; Waddington, G. In Experimental Thermochemistry; Rossini F. D., Ed.; Interscience: New York, 1956; Vol. 1, Chapter 5.

(21) Loss, R. D. Pure Appl. Chem. 2003, 75, 1107.

(22) Burkinshaw, P. M.; Mortiner, C. T. J. Chem. Soc., Dalton Trans. 1984, 75 .

(23) Ribeiro da Silva, M. A. V.; Gonçalves, J. M. J. Chem. Thermodyn. 1998, 30, 1465.

(24) Ribeiro da Silva, M. A. V.; Ferrão, M. L. C. C. H.; Monte, M. J. S.; Gonçalves, J. M.; Jiye, F. J. Chem. Thermodyn. 1999, 31, 1067.

(25) Malaspina, L.; Bardi, G.: Gigli, R. J. Chem. Thermodyn. 1974, 6, 1053.

(26) Sauerbrey, G. Z. Phys. 1959, 155, 206.

(27) Becke, A. D. J. Chem. Phys. 1993, 98, 5648.

(28) Becke, A. D. Phys. Rev. A 1988, 38, 3098.

(29) Lee, C.; Yang, W.; Parr, R. G. Phys. Rev. B 1980, 37, 785.

(30) Frisch, M. J.; Trucks, G. W.; Schlegel, H. B.; Scuseria, G. E.; Robb, M. A.; Cheeseman, J. R.; Montgomery, J. A., Jr.; Vreven, T.; Kudin, K. N.; Burant, J. C.; Millam, J. M.; Iyengar, S. S.; Tomasi, J.; Barone, V.; Mennucci, B.; Cossi, M.; Scalmani, G.; Rega, N.; Petersson, G. A.; Nakatsuji, H.; Hada, M.; Ehara, M.; Toyota, K.; Fukuda, R.; Hasegawa, J.; Ishida, M.; Nakajima, T.; Honda, Y.; Kitao, O.; Nakai, H.; Klene, M.; Li, X.; Knox, J. E.; Hratchian, H. P.; Cross, J. B.; Bakken, V.; Adamo, C.; Jaramillo, J.; Gomperts, R.; Stratmann, R. E.; Yazyev, O.; Austin, A. J.; Cammi, R.; Pomelli, C.; Ochterski, J. W.; Ayala, P. Y.; Morokuma, K.; Voth, G. A.; Salvador, P.; Dannenberg, J. J.; Zakrzewski, V. G.; Dapprich, S.; Daniels, A. D.; Strain, M. C.; Farkas, O.; Malick, D. K.; Rabuck, A. D.; Raghavachari, K.; Foresman, J. B.; Ortiz, J. V.; Cui, Q.; Baboul, A. G.; Clifford, S.; Cioslowski, J.; Stefanov, B. B.; Liu, G.; Liashenko, A.; Piskorz, P.; Komaromi, I.; Martin, R. L.; Fox, D. J.; Keith, T.; Al-Laham, M. A.; Peng, C. Y.; Nanayakkara, A.; Challacombe, M.; Gill, P. M. W.; Johnson, B.; Chen, W.; Wong, M. W.; Gonzalez, C.; Pople, J. A. Gaussian 03, revision C.01; Gaussian, Inc.: Wallingford, CT, 2004.

(31) Cox, J. D.; Wagman, D. D.; Medvedev, V. A. CODATA Key Values for Thermodynamics; Hemisphere: New York, 1989.

(32) Gomes, J. R. B.; Ribeiro da Silva, M. A. V. Int. J. Quantum Chem. 2005, 101, 860 .

(33) Gomes, J. R. B.; Amaral, L. M. P. F.; Ribeiro da Silva, M. A. V. Chem. Phys. Lett. 2005, 406, 154.

(34) Ribeiro da Silva, M. A. V.; Amaral, L. M. P. F.; Santos, A. F. L. O. M.; Gomes, J. R. B. J. Chem. Thermodyn. 2006, 38, 367.

(35) Ribeiro da Silva, M. A. V.; Amaral, L. M. P. F.; Santos, A. F. L. O. M.; Gomes, J. R. B. J. Chem. Thermodyn. 2006, 38, 748.

(36) Ribeiro da Silva, M. D. M. C.; Miranda, M. S.; Vaz, C. M. V.; Matos, M. A. R.; Acree, W. E., Jr. J. Chem. Thermodyn. 2005, 37, 49.

(37) Morais, V. M. F.; Miranda, M. S.; Matos, M. A. R. Org. Biomol. Chem. 2003, 1, 4329.

(38) Acree, W. E., Jr.; Ribeiro da Silva, M. D. M. C.; Pilcher, G. $J$ Phys. Chem. Ref. Data 2005, 34, 553.

(39) Ribeiro da Silva, M. A. V.; Morais, V. M. F.; Matos, M. A. R.; Rio, C. M. A.; Piedade, C. M. G. S. Struct. Chem. 1996, 7, 329. 